\title{
Humidity-Sensing Properties of an 1D Antiferromagnetic Oxalate-Bridged Coordination Polymer of Iron(III) and Its Temperature-Induced Structural Flexibility
}

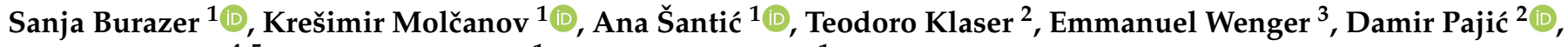 \\ Zvonko Jagličić $^{4,5}$, Jasminka Popović ${ }^{1}$ and Marijana Jurić ${ }^{1, *}$ \\ 1 Ruđer Bošković Institute, Bijenička cesta 54, 10000 Zagreb, Croatia; Sanja.Burazer@irb.hr (S.B.); \\ Kresimir.Molcanov@irb.hr (K.M.); asantic@irb.hr (A.Š.); Jasminka.Popovic@irb.hr (J.P.) \\ 2 Department of Physics, Faculty of Science, University of Zagreb, Bijenička cesta 32, 10000 Zagreb, Croatia; \\ tklaser@phy.hr (T.K.); dpajic@phy.hr (D.P.) \\ 3 CRM2 CNRS, UMR 7036, Institut Jean Barriol, Université de Lorraine, BP 70239 Vandoeuvre-lès-Nancy, \\ France; emmanuel.wenger@univ-lorraine.fr \\ 4 Institute of Mathematics, Physics and Mechanics, Jadranska 19, 1000 Ljubljana, Slovenia; \\ zvonko.jaglicic@imfm.si or zvonko.jaglicic@fgg.uni-lj.si \\ 5 Faculty of Civil and Geodetic Engineering, University of Ljubljana, Jamova 2, 1000 Ljubljana, Slovenia \\ * Correspondence: Marijana.Juric@irb.hr; Tel.: +385-1-456-1189
}

Citation: Burazer, S.; Molčanov, K.; Šantić, A.; Klaser, T.; Wenger, E.; Pajić, D.; Jagličić, Z.; Popović, J.; Jurić, M. Humidity-Sensing Properties of an 1D Antiferromagnetic Oxalate-Bridged Coordination Polymer of Iron(III) and Its Temperature-Induced Structural Flexibility. Materials 2021, 14, 5543. https://doi.org/10.3390/ma14195543

Academic Editor: Anastasios J. Tasiopoulos

Received: 2 September 2021

Accepted: 22 September 2021

Published: 24 September 2021

Publisher's Note: MDPI stays neutral with regard to jurisdictional claims in published maps and institutional affiliations.

Copyright: (c) 2021 by the authors. Licensee MDPI, Basel, Switzerland. This article is an open access article distributed under the terms and conditions of the Creative Commons Attribution (CC BY) license (https:// creativecommons.org/licenses/by/ $4.0 /)$
Abstract: A novel one-dimensional (1D) oxalate-bridged coordination polymer of iron(III), $\left\{\left[\mathrm{NH}\left(\mathrm{CH}_{3}\right)\right.\right.$ $\left.\left.\left(\mathrm{C}_{2} \mathrm{H}_{5}\right)_{2}\right]\left[\mathrm{FeCl}_{2}\left(\mathrm{C}_{2} \mathrm{O}_{4}\right)\right]\right\}_{n}(\mathbf{1})$, exhibits remarkable humidity-sensing properties and very high proton conductivity at room temperature $\left(2.70 \times 10^{-4}(\Omega \cdot \mathrm{cm})^{-1}\right.$ at $298 \mathrm{~K}$ under $93 \%$ relative humidity), in addition to the independent antiferromagnetic spin chains of iron(III) ions bridged by oxalate groups $\left(J=-7.58(9) \mathrm{cm}^{-1}\right)$. Moreover, the time-dependent measurements show that $\mathbf{1}$ could maintain a stable proton conductivity for at least $12 \mathrm{~h}$. Charge transport and magnetic properties were investigated by impedance spectroscopy and magnetization measurements, respectively. Compound $\mathbf{1}$ consists of infinite anionic zig-zag chains $\left[\mathrm{FeCl}_{2}\left(\mathrm{C}_{2} \mathrm{O}_{4}\right)\right]_{n}{ }^{n-}$ and interposed diethylmethylammonium cations $\left(\mathrm{C}_{2} \mathrm{H}_{5}\right)_{2}\left(\mathrm{CH}_{3}\right) \mathrm{NH}^{+}$, which act as hydrogen bond donors toward carbonyl oxygen atoms. Extraordinarily, the studied coordination polymer exhibits two reversible phase transitions: from the high-temperature phase $\mathrm{HT}$ to the mid-temperature phase $\mathbf{M T}$ at $\mathrm{T} \sim 213 \mathrm{~K}$ and from the mid-temperature phase $\mathbf{M T}$ to the low-temperature phase $\mathbf{L T}$ at $\mathrm{T}$ $\sim 120 \mathrm{~K}$, as revealed by in situ powder and single-crystal X-ray diffraction. All three polymorphs show large linear thermal expansion coefficients.

Keywords: oxalate-bridged coordination polymers; alkyl ammonium cations; single-crystal-to-singlecrystal transformations; proton conductivity; humidity-sensing property; antiferromagnetic spin chain

\section{Introduction}

Metal-organic coordination polymers, which have a wealth of multifunctional applications due to their immense structural diversity and flexibility, are currently being extensively studied. Multifunctional properties of these materials can be achieved by combining the intrinsic properties of the host, especially the magnetic ones, with additional functionalities derived from the selected guest molecules [1,2]. The oxalate group, $\mathrm{C}_{2} \mathrm{O}_{4}{ }^{2-}$, certainly represents an excellent tailoring tool due to its different coordination modes to metal centers, as well as its ability to mediate magnetic interactions between paramagnetic metal ions, as evidenced by a large number of oxalate-based transition metal species of different nuclearity, connectivity, and dimensionality, many of which possess tunable magnetic frameworks [3-5].

The importance of high proton conductivity in solid materials for use as humidity sensors, membranes in water electrolyzers, and especially in fuel cells was recognized some time ago, but achieving it remains a challenging task [6]. Recently, coordination polymers 
and metal-organic frameworks providing additional proton-conducting pathways were established, thereby opening new avenues for improving proton conductivity [7-11]. These systems can generally be obtained by introducing (i) the guest molecules (such as water) and counterions or acids into the voids, which helps to create intricate hydrogen-bonded networks and, thus, improve the proton conductivity, or (ii) other functional groups, such as $-\mathrm{COOH},-\mathrm{PO}_{3} \mathrm{H},-\mathrm{SO}_{3} \mathrm{H}$, and $-\mathrm{OH}$, which can better the acidity and hydrophilicity of the organic ligands and, thus, form an efficient proton transport pathway [8].

In particular, it has been shown that bifunctional molecular materials, which possess high conductivity in addition to magnetic properties, can be achieved on a two- (2D) or three-dimensional (3D) oxalate-bridged coordination polymer platform. The formation of the 3D oxalate-based anionic networks with the original topologies and an unusual $\mathrm{Mn}^{\mathrm{II}} / \mathrm{Cr}^{\mathrm{III}}$ ratio leads to the appearance of ferro- and antiferromagnetic long-range order, while the presence of water, ammonium, or imidazolium molecules within the channels enables high humidity-dependent proton conductivity of these compounds [12-14]. It has been shown that the proton conductivity of layered 2D oxalate-bridged $\left[\mathrm{M}^{\mathrm{II}} \mathrm{Cr}{ }^{\mathrm{III}}\right]\left(\mathrm{M}^{\mathrm{II}}=\mathrm{Fe}\right.$, $\mathrm{Mn}$ ) frameworks with carboxyl group-bearing cationic components can be improved by increasing the hydrophilicity of the ions [15]. Similarly, the introduction of hydroxyl groups into the alkyl residue of ammonium ions in the $2 \mathrm{D}$ oxalate network $\left[\mathrm{M}^{\mathrm{II}} \mathrm{Cr}{ }^{\mathrm{III}}\right]\left(\mathrm{M}^{\mathrm{II}}=\mathrm{Mn}^{\mathrm{II}}\right.$, $\mathrm{Fe}^{\mathrm{II}}, \mathrm{Co}^{\mathrm{II}}$ ) led to the formation of hydrophilic layers that enabled conductive pathways for protons [16]. The role of $\mathrm{NH}_{4}{ }^{+}$in the formation of efficient hydrogen-bond networks in the 2D oxalate-bridged polymer of zinc(II), which indeed provides high proton conductivity, was investigated by exchanging ammonium ions, which are typical proton conductors, with non-hydrogen-bonding potassium ions $[17,18]$. The effect of crystallization water molecules on proton conduction of this coordination polymer has also been studied [19]. Furthermore, constructed 3D dimethylammonium-containing oxalate-bridged coordination polymers have shown high proton conductivity due to the formation of extensive hydrogen-bonded networks [8,20-22].

While high proton conductivity is often found in oxalate-based 2D and 3D assemblies, few examples emerge once the dimensionality lowers to one-dimensional (1D) polymers $[7,8]$ such as $\left[\mathrm{Fe}\left(\mathrm{H}_{2} \mathrm{O}\right)_{2}\left(\mathrm{C}_{2} \mathrm{O}_{4}\right)\right]_{n}$, with coordinated water molecules forming a well-ordered $1 \mathrm{D}$ water nanoarray, allowing rational design of coordination polymers useful for solid electrolytes [23].

Here, we present an oxalate-bridged 1D coordination polymer $\left\{\left[\mathrm{NH}\left(\mathrm{CH}_{3}\right)\left(\mathrm{C}_{2} \mathrm{H}_{5}\right)_{2}\right]\left[\mathrm{FeCl}_{2}\left(\mathrm{C}_{2} \mathrm{O}_{4}\right)\right]\right\}$ (1) that exhibits antiferromagnetic spin chains of the host iron(III) anions, $\left[\mathrm{FeCl}_{2}\left(\mathrm{C}_{2} \mathrm{O}_{4}\right)\right]_{n}{ }^{n-}$, while the alkyl ammonium counterions and guest molecules give rise to high proton conductivity at room temperature (RT), which is quite unusual for 1D structural and magnetic arrangements. Strikingly, the proton conductivity of $\mathbf{1}$ increases by more than five orders of magnitude with increasing relative humidity (RH), achieving $2.70 \times 10^{-4}(\Omega \cdot \mathrm{cm})^{-1}$ at $298 \mathrm{~K}$ and $93 \% \mathrm{RH}$. In addition, the title compound also shows great structural versatility with several single-crystal-to-single-crystal transformations induced by temperature.

\section{Experimental}

\subsection{Materials and Physical Measurements}

All used chemicals were procured from commercial sources and used without further purification. The infrared spectrum was recorded using a KBr pellet by a Bruker Alpha-T spectrometer in the $4000-350 \mathrm{~cm}^{-1}$ range. Thermal properties were investigated from RT to $1073 \mathrm{~K}$ in synthetic air, with a Shimadzu DTG-60H analyzer (heating rate of $10^{\circ} \mathrm{C} \cdot \mathrm{min}^{-1}$ ).

\subsection{Synthetic Procedures}

To an aqueous solution $(10 \mathrm{~mL})$ containing $\mathrm{FeCl}_{3}(0.1622 \mathrm{mg} ; 1 \mathrm{mmol})$ and $\mathrm{H}_{2} \mathrm{C}_{2} \mathrm{O}_{4} \cdot 2 \mathrm{H}_{2} \mathrm{O}$ $(0.1261 \mathrm{mg} ; 1 \mathrm{mmol})$, an amine, $\mathrm{NCH}_{3}\left(\mathrm{C}_{2} \mathrm{H}_{5}\right)_{2}(2.2 \mathrm{mmol} ; 0.27 \mathrm{~mL})$, was added. The reaction mixture was stirred for $10 \mathrm{~min}$, after which it was filtered to remove a small amount of reddish precipitate, if formed. From a clear solution, yellow rod-like single crystals of $\left\{\left[\mathrm{NH}\left(\mathrm{CH}_{3}\right)\left(\mathrm{C}_{2} \mathrm{H}_{5}\right) 2\right]\left[\mathrm{FeCl}_{2}\left(\mathrm{C}_{2} \mathrm{O}_{4}\right)\right]\right\}_{n}$ (1) formed in 2 weeks via slow evaporation. They were quickly washed using a small amount of ethanol and dried in air. The yield was $40 \%$. Main IR 
absorptions bands $\left(\mathrm{KBr}, \mathrm{cm}^{-1}\right)$ were as follows: 3120-2815 $(v(\mathrm{NH})$ and $v(\mathrm{CH})), 1696$ and 1608 $\left(v_{a s}(\mathrm{CO})\right), 1500-1375(v(\mathrm{CN})), 1348$ and $1205\left(v_{s}(\mathrm{CO})\right), 801(\delta(\mathrm{OCO}))[24]$.

\subsection{Single-Crystal X-ray Structural Study}

Single-crystal measurement of compound HT-1 (243 K) was performed on an Oxford Diffraction Xcalibur Nova R diffractometer (Oxford Diffraction, Wroclaw, Poland) $(\lambda=1.54179 \AA$, microfocus $\mathrm{Cu}$ tube) equipped with an Oxford Instruments CryoJet liquid-nitrogen cooling device (Oxford Instruments, Abingdon, UK). Program package CrysAlis PRO was used for data reduction and numerical absorption correction [25]. Data collections for phases LT-1 (100 K) and MT-1 $(180 \mathrm{~K})$ were carried out on a Bruker D8 Venture $(\lambda=0.71073 \AA$, microfocus Mo tube) diffractometer (Bruker AXS, Madison, WI, USA) equipped with an Oxford Cryosystems Cryostream Series 700 liquid-nitrogen cooling device (Oxford Cryosystems, Oxford, UK). Data reduction and absorption correction were preformed using Bruker SAINT software package [26]. The structures were solved using SHELXS97 [27] and refined with SHELXL-2017 [28]. Models were refined using the full-matrix least squares refinement; all non-hydrogen atoms were refined anisotropically. Hydrogen atoms were located in a difference Fourier map and refined either as riding entities or a mixture of free restrained and riding entities. Undisordered structure MT-1 was refined without restraints, while disordered cations in LT-1 and HT-1 structures were refined using rigid-body restraints (commands SIMU and DELU in SHELXS97); the $\mathrm{C}-\mathrm{C}$ and $\mathrm{C}-\mathrm{N}$ bonds were restrained to $1.54(2)$ and $1.45(2) \AA$, respectively. In addition, bond angles in cations in LT-1 were restrained to $\mathrm{C}-\mathrm{C}$ and $\mathrm{C}-\mathrm{N}$ distances of 2.30(4) $\AA$. Molecular geometry calculations were performed by PLATON [29,30], and molecular graphics were prepared using ORTEP-3 [31], and Mercury [32]. The crystallographic and refinement data for the structures reported in this work are given in Table 1.

\subsection{Powder X-ray Structural Study}

Temperature-induced structural changes were followed by in situ X-ray powder diffraction on a Bruker D8 Discover diffractometer (Bruker, Karlsruhe, Germany) equipped with LYNXEYE XE-T detector in Bragg-Brentano geometry (Bruker, Karlsruhe, Germany). Data were collected in the $2 \theta$ range $19.5-33^{\circ}$ in the temperature range from $273 \mathrm{~K}$ to $80 \mathrm{~K}$.

Crystal structures were refined using the Rietveld method in HighScoreXpert Plus (Version 4.5, March 2016). The thermal expansion coefficients were calculated from the refined unit-cell parameters obtained from the variable-temperature diffraction data. The axial thermal expansion coefficients along the principal axes were calculated using software PASCal [33].

\subsection{Magnetization Study}

Magnetic properties were studied on polycrystalline powder samples of $\mathbf{1}$ using a commercial MPMS 5 superconducting quantum interferometer device (SQUID) magnetometer (Quantum Design, San Diego, CA, USA). The pressed pellet was directly inserted into a measuring straw without any glue, such that the measured signal came only from the sample. The temperature dependence of the magnetization $M(T)$ was measured in the temperature range $2-300 \mathrm{~K}$ in two modes; first, the sample was cooled in zero field and measured in the applied field $H$ during heating (so-called ZFC curve), and then the sample was cooled in the same field in which the $M(T)$ was measured afterward during heating (so-called FC curve). The magnetic hysteresis $M(H)$ was measured at several stable temperatures in magnetic fields up to $5 \mathrm{~T}$. No irreversibility was observed in both $M(T)$ and $M(H)$ measurements, indicating that there is no long-range ordering or spin freezing. For the calculation of the molar magnetic susceptibility $\chi$, the measurement of $M(T)$ in a field of 1000 Oe was used to ensure both a linear $M(H)$ response and a sufficiently high signal to reduce the influence of noise, such that the calculated $\chi(T)=M(T) / H$ was a reliable physical function. A relatively broad maximum around $45 \mathrm{~K}$ in the $\chi(T)$ dependence points to the existence of an antiferromagnetic interaction and indicates the low-dimensional magnetic structure. In accordance with the chain structure of the iron(III) ions, the Fisher formula [34] for the susceptibility of magnetic chains consisting of large spins, 
Table 1. Crystallographic data and structure refinement details for variable-temperature X-ray diffraction of compound $\left\{\left[\mathrm{NH}\left(\mathrm{CH}_{3}\right)\left(\mathrm{C}_{2} \mathrm{H}_{5}\right)_{2}\right]\left[\mathrm{FeCl}_{2}\left(\mathrm{C}_{2} \mathrm{O}_{4}\right)\right]\right\}_{n}(\mathbf{1})$.

\begin{tabular}{|c|c|c|c|}
\hline Compound & LT-1 (100 K) & MT-1 (180 K) & HT-1 (243 K) \\
\hline Empirical formula & $\mathrm{C}_{7} \mathrm{H}_{14} \mathrm{Cl}_{2} \mathrm{FeNO}_{4}$ & $\mathrm{C}_{7} \mathrm{H}_{14} \mathrm{Cl}_{2} \mathrm{FeNO}_{4}$ & $\mathrm{C}_{7} \mathrm{H}_{14} \mathrm{Cl}_{2} \mathrm{FeNO}_{4}$ \\
\hline Formula wt. $\left(\mathrm{g} \cdot \mathrm{mol}^{-1}\right)$ & 302.94 & 302.94 & 302.94 \\
\hline Color & yellow & yellow & yellow \\
\hline Crystal dimensions / $\mathrm{mm}$ & $0.18 \times 0.09 \times 0.07$ & $0.20 \times 0.18 \times 0.09$ & $0.20 \times 0.18 \times 0.08$ \\
\hline Space group & $P 2_{1} / n$ & $P 2_{1} / c$ & $P 2_{1} / c$ \\
\hline$a(\AA)$ & $14.962(3)$ & $8.720(2)$ & $8.5125(8)$ \\
\hline$b(\AA)$ & $10.791(2)$ & $9.762(2)$ & $10.7755(14)$ \\
\hline$c(\AA)$ & $16.944(3)$ & $14.830(3)$ & $14.9703(16)$ \\
\hline$\alpha\left(^{\circ}\right)$ & 90 & 90 & 90 \\
\hline$\beta\left(^{\circ}\right)$ & $105.96(3)$ & $95.43(3)$ & $104.798(9)$ \\
\hline$\gamma\left({ }^{\circ}\right)$ & 90 & 90 & 90 \\
\hline $\mathrm{Z}$ & 8 & 4 & 4 \\
\hline$V\left(\AA^{3}\right)$ & $2630.1(9)$ & $1256.8(5)$ & $1327.6(3)$ \\
\hline$D_{\text {calc }}\left(\mathrm{g} \cdot \mathrm{cm}^{-3}\right)$ & 1.530 & 1.601 & 1.516 \\
\hline$\lambda(\AA)$ & $0.71073(\mathrm{MoK} \alpha)$ & $0.71073(\mathrm{MoK} \alpha)$ & $1.54179(\mathrm{CuK} \alpha)$ \\
\hline$\mu\left(\mathrm{mm}^{-1}\right)$ & 1.547 & 1.618 & 12.807 \\
\hline$\Theta$ range $\left(^{\circ}\right)$ & $2.26-27.57$ & $2.35-26.53$ & $5.12-74.32$ \\
\hline$T(\mathrm{~K})$ & 100(2) & $180(2)$ & 243(2) \\
\hline Diffractometer type & D8 Venture & D8 Venture & Xcalibur Nova \\
\hline & $19<h<18$ & $-10<h<10$ & $-10<h<6$ \\
\hline Range of $h, k, l$ & $\begin{array}{c}13<k<13 \\
-21<l<22\end{array}$ & $\begin{array}{l}-12<k<10 \\
-18<l<17\end{array}$ & $\begin{array}{l}-13<k<13 \\
-18<l<17\end{array}$ \\
\hline Reflections collected & 58295 & 10852 & 5948 \\
\hline Independent reflections & 6028 & 2595 & 2423 \\
\hline Observed reflections $(I \geq 2 \sigma)$ & 4917 & 1937 & 1440 \\
\hline Absorption correction & None & None & Multi-scan \\
\hline$T_{\min }, T_{\max }$ & - & - & $0.21266 ; 1.0000$ \\
\hline $\mathrm{R}_{\text {int }}$ & 0.0597 & 0.0590 & 0.0542 \\
\hline $\mathrm{R}(\mathrm{F})$ & 0.0349 & 0.0416 & 0.0873 \\
\hline $\mathrm{R}_{\mathrm{w}}\left(\mathrm{F}^{2}\right)$ & 0.0904 & 0.1155 & 0.2990 \\
\hline Goodness of fit & 1.043 & 1.066 & 1.010 \\
\hline $\mathrm{H}$ atom treatment & Mixed & Constrained & Constrained \\
\hline No. of parameters & 315 & 139 & 147 \\
\hline No. of restraints & 91 & 0 & 77 \\
\hline$\Delta \rho_{\max }, \Delta \rho_{\min }\left(\mathrm{e} \AA^{-3}\right)$ & $0.890 ;-0.520$ & $0.570 ;-0.467$ & $0.444 ;-0.381$ \\
\hline
\end{tabular}

$$
\chi_{F}(T)=\frac{N_{A} g^{2} \mu_{B}^{2} S(S+1)}{3 k_{B} T} \frac{1+u}{1-u}
$$

where

$$
u=\operatorname{coth}\left[\frac{J S(S+1)}{k_{B} T}\right]-\left[\frac{k_{B} T}{J S(S+1)}\right]
$$

was used to fit the measured dependence. Here, $S=5 / 2$ is large enough to ensure the validity of the Fisher formula. $J$ is the exchange interaction between the neighboring spins used in the spin interaction Hamiltonian $H=-J \sum_{i} \vec{S}_{i} \cdot \vec{S}_{i+1}$, and other symbols have their usual meaning. Temperatures above $25 \mathrm{~K}$ were used in the fitting, because the Fisher function itself is limited to the temperatures not far below the maximum of the susceptibility $(\approx J)$. For the best-fitting curve, the obtained value for the intra-chain super-exchange interaction between the neighboring $\mathrm{Fe}^{3+}$ ions was $J=(-7.58 \pm 0.09) \mathrm{cm}^{-1}$ $(-10.9 \pm 0.2) \mathrm{K}$, with $g=(2.01 \pm 0.01)$. The small rise in $\chi$ with cooling to the lowest temperatures came from the impurities. Fitting with the paramagnetic term added to the $\chi_{\mathrm{F}}$ was not successful because of two possible effects: the Fisher function was not valid for the lowest temperatures, and the impurities might have been of some other 
origin but not paramagnetic. Comparing the shape of the $\chi(T)$ dependence with another $S=5 / 2$ spin chain system [35], an impurity molar ratio well below $1 \%$ can be estimated. Although the fitted $\chi_{\mathrm{F}}$ described the measured $\chi(T)$ dependence very well, extension of the Fisher function with the mean field correction was also tried in order to probe if there was some observable inter-chain interaction. The conclusion was that there were no detectable interactions between the chains, as could already be concluded from the good overlap of the Fisher function with the measured data.

\subsection{Proton Conductivity Study}

The conductivity of compound $\mathbf{1}$ was measured by impedance spectroscopy (Novocontrol Alpha-AN Dielectric Spectrometer, Novocontrol Technologies GmbH \& Co. KG, Hundsangen, Germany) from $0.01 \mathrm{~Hz}$ to $1 \mathrm{MHz}$ at $25^{\circ} \mathrm{C}$ at different relative humidity values: $61 \%$ (air, ambient conditions), $75 \%, 84 \%$, and $93 \%$. The relative humidity inside the sample cell was obtained using saturated aqueous solutions of different salts: $\mathrm{NaCl}(\mathrm{RH}=75 \%), \mathrm{KCl}(\mathrm{RH}$ $=84 \%)$, and $\mathrm{KNO}_{3}(\mathrm{RH}=93 \%)$. In addition, the impedance spectra of compound 1 were measured in dry nitrogen at temperatures from $-90^{\circ} \mathrm{C}$ to $70{ }^{\circ} \mathrm{C}$ (temperature step: $10^{\circ} \mathrm{C}$ ) and in the frequency range from $0.01 \mathrm{~Hz}$ to $1 \mathrm{MHz}$. The measurements were performed on polycrystalline sample pressed into pellet of approximate thickness $0.8 \mathrm{~mm}$. For the electrical contacts, gold electrodes ( $3.8 \mathrm{~mm}$ in diameter) were sputtered on the opposite surfaces of the pellet. The impedance spectra were analyzed by equivalent circuit modeling using the complex nonlinear least-squares fitting procedure (ZView software). From the values of electrical resistance $(R)$ and electrode dimensions (A is the electrode area, and $\mathrm{d}$ is the sample thickness) the DC conductivity was calculated according to the following equation: $\sigma_{\mathrm{DC}}=d /(A \cdot R)$.

\section{Results and Discussion}

\subsection{Synthesis and Crystal Structures of Compound 1}

Yellow rod-shaped crystals of compound 1 were obtained via slow evaporation of an aqueous solution containing a mixture of $\mathrm{FeCl}_{3}(1 \mathrm{mmol}), \mathrm{H}_{2} \mathrm{C}_{2} \mathrm{O}_{4} \cdot \mathrm{H}_{2} \mathrm{O}(1 \mathrm{mmol})$, and $\left(\mathrm{C}_{2} \mathrm{H}_{5}\right)_{2}\left(\mathrm{CH}_{3}\right) \mathrm{N}$ ( $2.2 \mathrm{mmol})$. It is important to note that compound 1 could not be formed without excess amine. It remained stable up to $420 \mathrm{~K}$, when the main mass loss occurred in two steps, followed by strong exothermic effects ending around $973 \mathrm{~K}$ (Figure S1).

During preliminary collection of single-crystal X-ray diffraction data of $\mathbf{1}$ at RT and later on at $100 \mathrm{~K}$, a phase transformation was observed; to gain additional insight into temperature-induced structural transformation of $\mathbf{1}$, in situ X-ray powder diffraction (XRPD) measurements were performed (Figure 1a). In situ variable-temperature XRPD revealed that compound 1 exhibits two reversible phase transitions: from the hightemperature phase $\mathbf{H T}$ to the mid-temperature phase $\mathbf{M T}$ at $T \sim 213 \mathrm{~K}$, and from the mid-temperature phase $\mathbf{M T}$ to the low-temperature $\mathbf{L T}$ phase at $\mathrm{T} \sim 120 \mathrm{~K}$. The structures of HT-1, MT-1, and LT-1 were determined by single-crystal X-ray diffraction at $243 \mathrm{~K}, 180 \mathrm{~K}$, and $100 \mathrm{~K}$, respectively. The crystal data and details of the data collections and refinements for the reported phases are summarized in Table 1.

Rietveld structure refinement of the powder data at each $T$ was performed using initial structural models for HT-1, MT-1, and LT-1 as determined by single-crystal diffraction (Figure 1b). The presence of the high-temperature polymorph HT-1 was observed in the temperature range from $273 \mathrm{~K}$ to $233 \mathrm{~K}$. At $213 \mathrm{~K}$, sample contained both HT-1 and MT-1 phases (33.2 $\mathrm{wt} \%$ HT-1 and $66.8 \mathrm{wt} \%$ MT-1). The mid-temperature polymorph remained stable down to $120 \mathrm{~K}$, when the transformation to the low-temperature phase LT-1 occurred (78.5 wt $\%$ MT-1 and $21.5 \mathrm{wt} . \%$ LT-1). The low-temperature polymorph remained stable down to $80 \mathrm{~K}$. During the heating run, phase transitions were again observed at $T \sim 120 \mathrm{~K}$ and $T \sim 213 \mathrm{~K}$; however, the quantitative composition was slightly different from that found during the cooling run, indicating a small hysteresis in the temperature of the phase transition (Figure 1). 

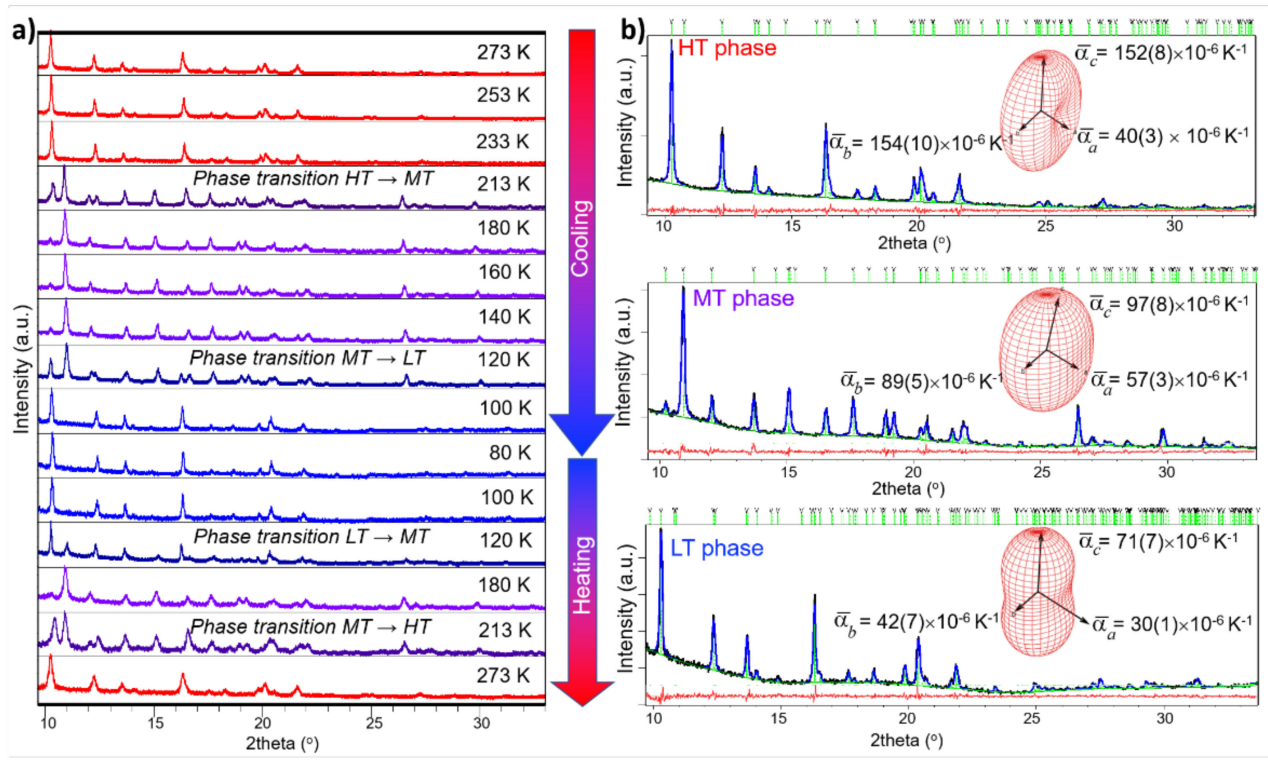

Figure 1. (a) In situ variable-temperature XRPD data of 1 collected in temperature range from 273 to $80 \mathrm{~K}$ during the cooling and heating run. Diffraction patterns of HT-1, MT-1, and LT-1 are given in red, purple, and blue, respectively. (b) Rietveld refinements for HT-1, MT-1, and LT-1 at $T=273,180$, and $100 \mathrm{~K}$, respectively. Experimental data are given by a black line, the calculated pattern is shown in blue, and the red line represents the difference curve. Green vertical marks show the positions of Bragg reflections. The thermal expansivity indicatrix and corresponding thermal expansion coefficients for each phase are shown in insets.

Phases HT and MT crystallized in a $P 2_{1} / c$ space group, while $\mathbf{L T}$ crystallized in $P 2_{1} / n$ (Table 1), with all three comprising $\left[\mathrm{FeCl}_{2}\left(\mathrm{C}_{2} \mathrm{O}_{4}\right)\right]_{n}{ }^{n-}$ chains packed in the same fashion and diethylmethylammonium cations $\left(\mathrm{CH}_{3}\right)\left(\mathrm{C}_{2} \mathrm{H}_{5}\right)_{2} \mathrm{NH}^{+}$located between them (Figure 2).

The temperature dependence of the unit-cell parameters is given in Table S1, while the thermal expansion behavior for each phase is represented by the thermal expansivity indicatrices shown as insets in Figure 1. It is noteworthy that all three polymorphs, but especially HT-1, exhibited large linear thermal expansion coefficients along the $b$ - and $c$-directions (Figure 1b). Molecular crystals usually exhibit a thermal expansion coefficient in the range of $20 \times 10^{-6} \mathrm{~K}^{-1}$, but large thermal expansions have recently been reported for (phenylazophenyl)palladium hexaflouracetyacetonate $\left(260 \times 10^{-6} \mathrm{~K}^{-1}\right)$ [36], $N^{\prime}-2$ propylidene-4-hydroxybenzohydrazide $\left(360 \times 10^{-6} \mathrm{~K}^{-1}\right)$ [37], and a copper(II) complex with imidazoliums $\left(346 \times 10^{-6} \mathrm{~K}^{-1}\right)$ [38].

Compound $\left\{\left[\mathrm{NH}\left(\mathrm{CH}_{3}\right)\left(\mathrm{C}_{2} \mathrm{H}_{5}\right)_{2}\right]\left[\mathrm{FeCl}_{2}\left(\mathrm{C}_{2} \mathrm{O}_{4}\right)\right]\right\}_{n}$ (1) comprises infinite anionic chains $\left[\mathrm{FeCl}_{2}\left(\mathrm{C}_{2} \mathrm{O}_{4}\right)\right]_{n}{ }^{n-}$ and diethylmethylammonium cations $\left(\mathrm{C}_{2} \mathrm{H}_{5}\right)_{2}\left(\mathrm{CH}_{3}\right) \mathrm{NH}^{+}$. Each iron(III) center is coordinated by two oxalate ligands in a cis arrangement and two terminal $\mathrm{Cl}$ ligands occupying the remaining two positions (also in a cis fashion). Due to an approximate $C_{2}$ symmetry of the coordination sphere, the Fe atoms act as stereogenic centers with alternating $\Lambda$ - and $\Delta$-configurations. Each oxalate ligand acts as a (bis)bidentate ligand bridging two $\mathrm{Fe}^{3+}$ ions with opposite configurations to form zig-zag chains (Figure 3); the $\mathrm{Fe}-\mathrm{O}$ and $\mathrm{Fe}-\mathrm{Cl}$ distances are similar to those previously reported [24,39-42]. Detailed geometric parameters describing the coordination of Fe ions in the three phases of compound $\mathbf{1}$ are given in Table S2. 

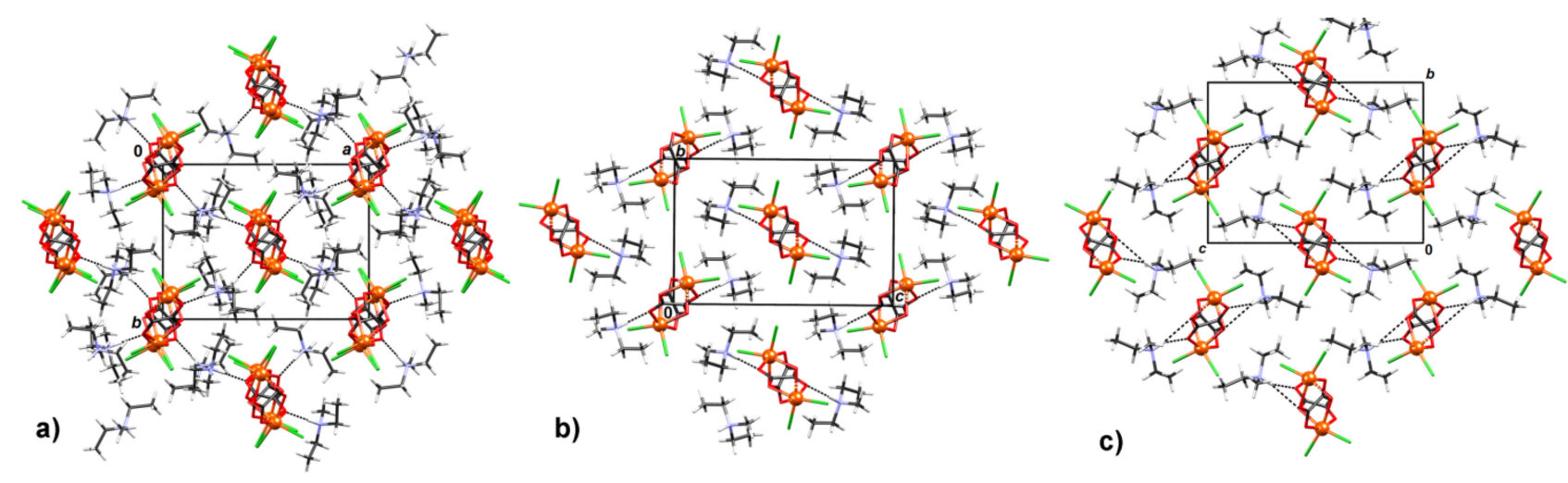

Figure 2. Packing of the $\left[\mathrm{FeCl}_{2}\left(\mathrm{C}_{2} \mathrm{O}_{4}\right)\right]_{n}{ }^{n-}$ chains in (a) LT, (b) MT, and (c) HT structures of coordination polymer $\left\{\left[\mathrm{NH}\left(\mathrm{CH}_{3}\right)\left(\mathrm{C}_{2} \mathrm{H}_{5}\right)_{2}\right]\left[\mathrm{FeCl}_{2}\left(\mathrm{C}_{2} \mathrm{O}_{4}\right)\right]\right\}_{n}$ (1) viewed in the direction of chains.
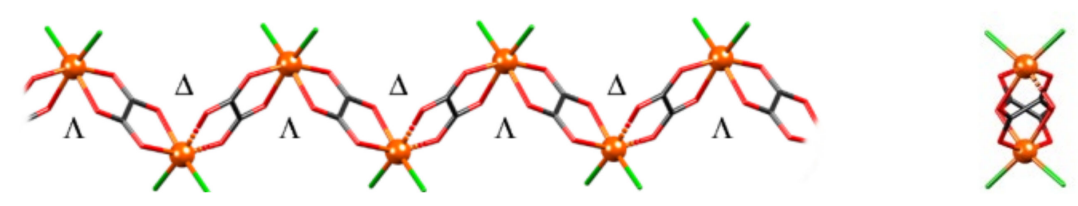

Figure 3. The $\left[\mathrm{FeCl}_{2}\left(\mathrm{C}_{2} \mathrm{O}_{4}\right)\right]_{n}{ }^{n-}$ chains in polymer $\mathbf{1}$ with indicated configuration of stereogenic iron(III) centers. A side-view of the chains is shown on the left, and a view along a chain is shown on the right.

The positions, as well as the arrangement of the cations acting as hydrogen bond donors toward the carbonyl oxygen atoms, were different in the three phases (Table S3). In the case of the HT structure, the cation was disordered over two positions; each donated a bifurcated hydrogen bond to a different $\left[\mathrm{FeCl}_{2}\left(\mathrm{C}_{2} \mathrm{O}_{4}\right)\right]_{n}{ }^{n-}$ chain (Figure 4c), whereas, in the MT structure, the cation was ordered and donated a single hydrogen bond (Figure $4 \mathrm{~b}$ ). The LT structure had two symmetry-independent cations $\left(Z^{\prime}=2\right)$ that had different conformations; in both, one ethyl group was disordered. Both cations served as donors of a single unbifurcated hydrogen bond (Figure 4a).

\subsection{Magnetic and Charge Transport Properties of Compound 1}

The chain structural ordering of iron(III) ions bridged by oxalate ligands was also confirmed by the temperature dependence of magnetic susceptibility, as shown in Figure 5. In agreement with the determined structure, the $\chi(T)$ is modeled using the Fisher formula [34]. Other relevant details related to the study of the magnetic properties of $\mathbf{1}$ are given in Section 2. The bestfitting curve was obtained for the antiferromagnetic exchange interaction $J=-7.58(9) \mathrm{cm}^{-1}$ between the neighboring iron(III) ions of spin 5/2 with $g=2.01$ (1) (Table S4). Linear $M(H)$ curves were consistent with antiferromagnetic coupling along the chains, and their slopes at different temperatures reflect the $\chi(T)$ behavior. In contrast to some oxalate-bridged chains of iron(III) containing different counterions $[24,39,40]$, which even exhibit a spontaneous magnetic order, no interaction between the chains was observed in $\mathbf{1}$. In the case of $\mathbf{1}$, the intra-chain interaction was stronger compared to most literature reports and approached the ideal Heisenberg spin-chain, as similarly found in [41]. 


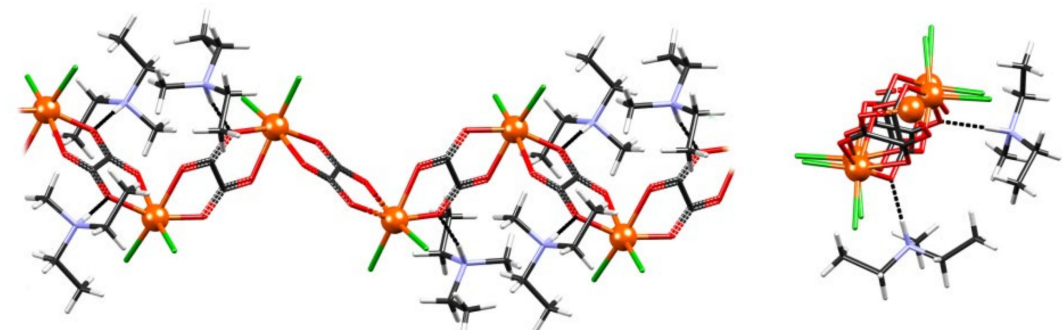

a)
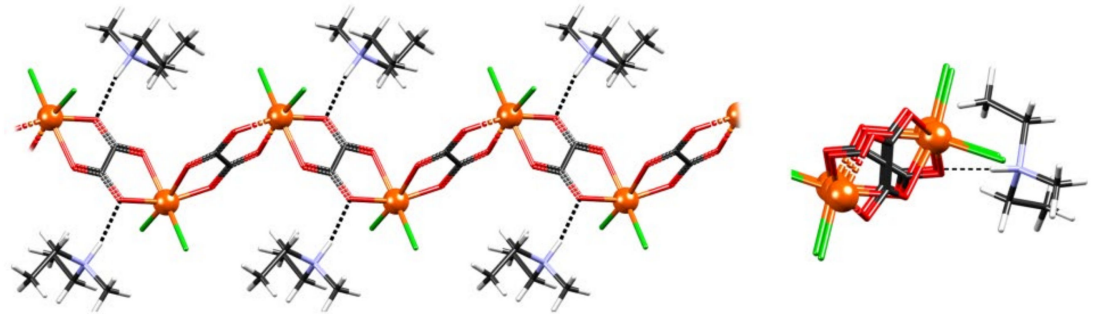

b)
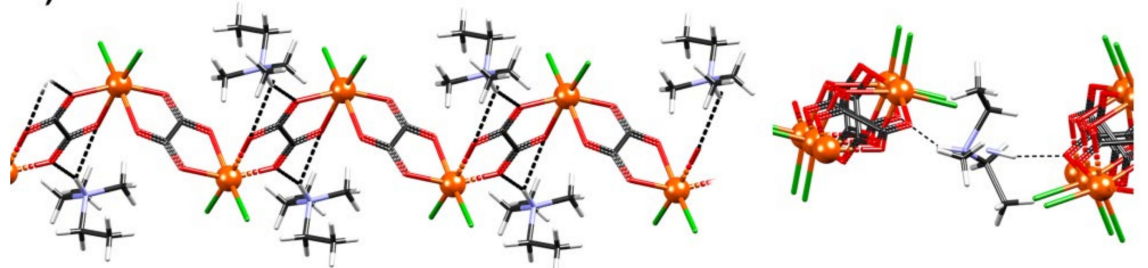

C)

Figure 4. The $\left[\mathrm{FeCl}_{2}\left(\mathrm{C}_{2} \mathrm{O}_{4}\right)\right]_{n}{ }^{n-}$ chains with hydrogen-bonded cations in (a) LT-1, (b) MT-1, and (c) HT-1 structures. The inset shows a close-up view of hydrogen bonds formed by the cation.

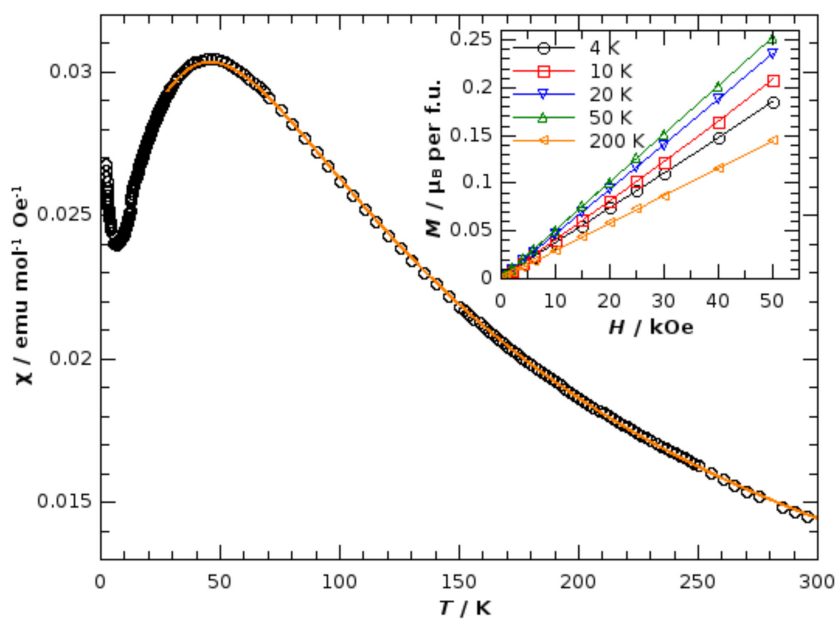

Figure 5. Temperature dependence of magnetic susceptibility, $\chi(T)$, measured in field of 1000 Oe. The orange solid line is the fitted curve. The inset shows the field dependence of magnetization, $M(H)$, expressed in Bohr magnetons per formula unit, at different temperatures, with visual guidelines.

The proton conductivity of $\mathbf{1}$ was evaluated by impedance spectroscopy using a compacted pellet of the powder sample at various humidity rates. With the increase in $\mathrm{RH}$ from $61 \%$ to $93 \%$ at $298 \mathrm{~K}$, the conductivity increases by more than five orders of magnitude and reaches the value of $2.70 \times 10^{-4}(\Omega \cdot \mathrm{cm})^{-1}$, indicating the excellent humidity-sensing properties of $\mathbf{1}$ (Figure 6). The conductivity of $\mathbf{1}$ is several orders of magnitude higher than other $1 \mathrm{D}$ coordination polymers $\left(\left\{\left[\mathrm{Zn}\left(\mathrm{C}_{10} \mathrm{H}_{2} \mathrm{O}_{8}\right)_{0.5}\left(\mathrm{C}_{10} \mathrm{~S}_{2} \mathrm{~N}_{2} \mathrm{H}_{8}\right)\right] \cdot 2 \mathrm{H}_{2} \mathrm{O}\right]\right\}_{n}\left(1.33 \times 10^{-7}\right.$ 
$(\Omega \cdot \mathrm{cm})^{-1}$ at RT and $\left.95 \% \mathrm{RH}\right)[43]$ and $\left[\mathrm{Mn}(\mathrm{dhbq})\left(\mathrm{H}_{2} \mathrm{O}\right)_{2}\right]_{n}\left(4 \times 10^{-5}(\Omega \cdot \mathrm{cm})^{-1}\right.$ at RT and $98 \% \mathrm{RH}$; dhbq $=2,5$-dihydroxy-1,4-benzoquinone]) [44], and it is rivaled only by $1 \mathrm{D}$ polymer $\left[\mathrm{Fe}\left(\mathrm{H}_{2} \mathrm{O}\right)_{2}\left(\mathrm{C}_{2} \mathrm{O}_{4}\right)\right]_{n}$, which achieved $1.3 \times 10^{-3}(\Omega \cdot \mathrm{cm})^{-1}$ at $98 \% \mathrm{RH}$ [23].

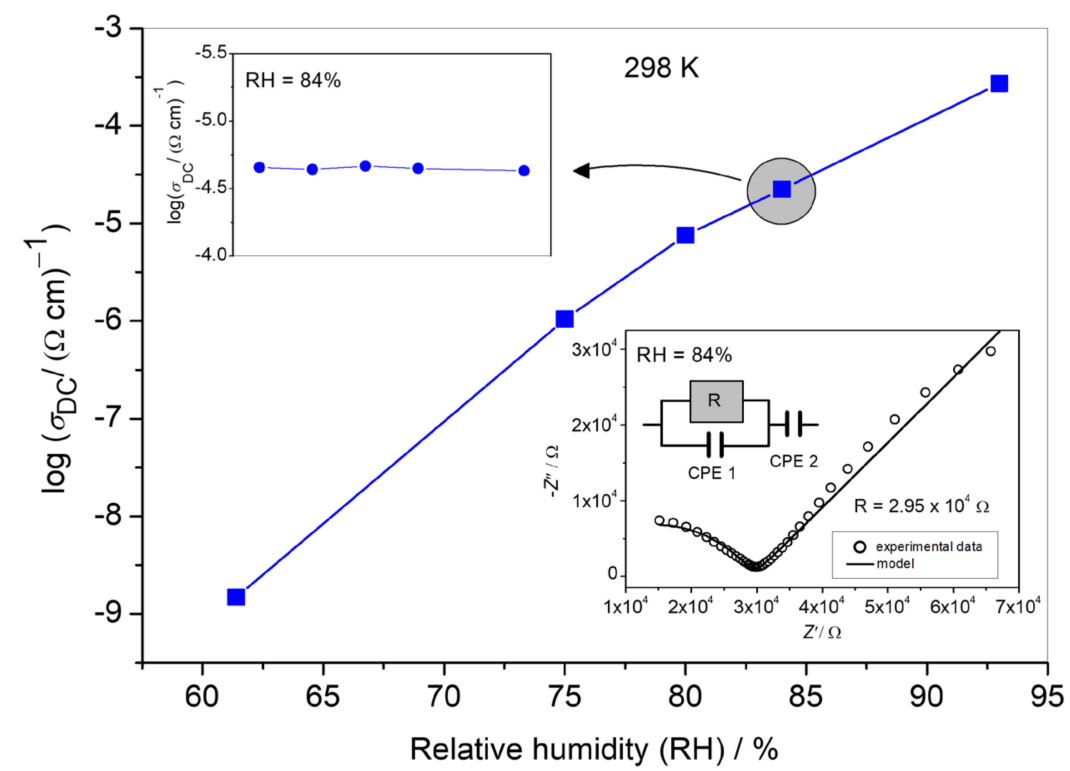

Figure 6. The proton conductivity of $\mathbf{1}$ as a function of relative humidity $(\mathrm{RH})$ at room temperature. The inset in the left corner shows the time-dependent proton conductivity of 1 at $84 \% \mathrm{RH}$. The inset in the right corner shows the Nyquist plot of 1 measured at $\mathrm{RH}=84 \%$. The impedance semicircle corresponds to the bulk response of the sample, and low-frequency spur is related to the blocking of protons at the surface of the electrodes. The corresponding equivalent electrical circuit consists of a parallel combination of resistor and constant phase element (CPE 1), which models the bulk response, and an additional constant phase element (CPE 2) in series, which is related to the spur. The Nyquist plots of $\mathbf{1}$ in other RH conditions are given in Figure S3.

The strong dependence of conductivity upon humidity indicates that efficient proton transfer plays a crucial role in achieving the high conductivity values of 1 [7-14]. No change in the structure of $\mathbf{1}$ was observed after treatment with humidity, indicating the stability of compound $\mathbf{1}$ (Figure S2). Moreover, the time-dependent measurements show that $\mathbf{1}$ could maintain stable proton conductivity for a period of least $12 \mathrm{~h}$, which is very beneficial for practical applications of this material (inset in Figure 6).

It is well established that water molecules have a pronounced effect on proton conductivity; as the number of waters increases, the conductivity increases due to the complex interpenetrating hydrogen bonding network, which enablse more efficient proton transfer [19]. Although not as pronounced as in the 3D frameworks, the best-performing 1D polymer $\left[\mathrm{Fe}\left(\mathrm{H}_{2} \mathrm{O}\right)_{2}\left(\mathrm{C}_{2} \mathrm{O}_{4}\right)\right]_{n}$ also featured an interesting intermolecular assembly: two water molecules coordinated axially to a ferrous ion forming a 1D ordered array, in addition to the $1 \mathrm{D}$ chain composed of ferrous ions and oxalate. In this regard, it is particularly important to note that the coordination polymer $\mathbf{1}$ contains neither coordinated nor crystalline water.

The hydrophilic channels were filled with diethylmethylammonium cations, which were not mutually interconnected and, thus, did not form a significant hydrogen bonding network (Figure 4.) Nevertheless, the room-temperature proton conductivity of $\mathbf{1}$ is still quite comparable to that of $\left[\mathrm{Fe}\left(\mathrm{H}_{2} \mathrm{O}\right)_{2}\left(\mathrm{C}_{2} \mathrm{O}_{4}\right)\right]_{n}$, suggesting that the alkyl ammonium cations, which were only connected to the $1 \mathrm{D}$ coordination polymer via hydrogen bonds, can also facilitate fast and efficient proton transfer, leading to the observed high proton conductivity in $\mathbf{1}$. 
Moreover, it should be noted that the proton conductivity of compound $\mathbf{1}$ is comparable to that of metal-organic frameworks (MOFs), which typically lies in the range $\sim 10^{-2}-10^{-4}(\Omega \cdot \mathrm{cm})^{-1}[7,14]$. Furthermore, it is close in value to the proton conductivity of covalent organic frameworks (COFs) with the best proton conductive performance of $\sim 10^{-1}-10^{-3}(\Omega \cdot \mathrm{cm})^{-1}[45]$.

Interestingly, the phase transition between the HT-1 and MT-1 phases was also evident in the temperature dependence of the conductivity measured in dry nitrogen, where two distinct ranges were observed: below $213 \mathrm{~K}$ characterized by a lower activation energy for the conductivity, $E_{\mathrm{a}}=0.42 \mathrm{eV}$, and above this temperature, where the activation energy was higher, $E_{\mathrm{a}}=0.62 \mathrm{eV}$ (Figure S4). It can be concluded that the as-prepared sample (HT-1) has a low intrinsic proton conductivity under ambient conditions, which is thermally activated with an activation energy of $0.62 \mathrm{eV}$, indicating a vehicle mechanism related to the diffusion of protons combined with the solvent acting as a vehicle. This is to be expected considering that the hydrogen-bonding array within the channel is not very complex and, thus, proton hopping is reduced. By lowering the temperature, the presence of the phase MT (Figure 1) decreases the activation energy, approaching the Grotthus mechanism [7,9]. It is likely that the different binding of the cations to the oxalate chains through hydrogen bonds affects the observed changes in the activation energy (Figure 4 and Table S3) of proton conductivity, indicating that the structural arrangement of MT-1 is more suitable for proton transport.

\section{Conclusions}

In summary, we reported an oxalate-bridged 1D material $\left\{\left[\mathrm{NH}\left(\mathrm{CH}_{3}\right)\left(\mathrm{C}_{2} \mathrm{H}_{5}\right)_{2}\right]\left[\mathrm{FeCl}_{2}\left(\mathrm{C}_{2} \mathrm{O}_{4}\right)\right]\right\}_{n}$ that exhibits great structural flexibility demonstrated by the appearance of three different polymorphic phases that possess additional multifunctional features; the compound consists of antiferromagnetic spin chains with strong exchange interactions but also shows excellent humidity-sensing properties and high proton conductivity. These studies show that the incorporation of a relatively simple yet quite flexible alkyl-substituted ammonium derivative as a counterion can lead to an emergence of important intrinsic properties of materials that are attractive for various applications.

Supplementary Materials: The following are available online at https://www.mdpi.com/article/ 10.3390/ma14195543/s1: Figure S1. The TG and DTA curves (heating and cooling) of compound 1 measured in synthetic air; Table S1. Temperature dependence of the unit-cell parameters for HT-1, MT-1, and LT-1 phases of coordination polymer $\left\{\left[\mathrm{NH}\left(\mathrm{CH}_{3}\right)\left(\mathrm{C}_{2} \mathrm{H}_{5}\right)_{2}\right]\left[\mathrm{FeCl}_{2}\left(\mathrm{C}_{2} \mathrm{O}_{4}\right)\right]\right\}_{n}(\mathbf{1})$; Table S2. Selected distances $(\AA)$ and angles $\left({ }^{\circ}\right)$ for the coordination sphere of the Fe ions in three phases of compound $\left\{\left[\mathrm{NH}\left(\mathrm{CH}_{3}\right)\left(\mathrm{C}_{2} \mathrm{H}_{5}\right)_{2}\right]\left[\mathrm{FeCl}_{2}\left(\mathrm{C}_{2} \mathrm{O}_{4}\right)\right]\right\}_{n}$ (1). Symmetry operators: (i) $1-x, 1-y, 2-z$; (ii) 1 $-x, 1-y, 1-z$; (iii) $2-x, 1-y, 1-z$; Table S3. Geometric parameters of hydrogen bonds $\left(\AA,^{\circ}\right)$ for three phases of compound $\left\{\left[\mathrm{NH}\left(\mathrm{CH}_{3}\right)\left(\mathrm{C}_{2} \mathrm{H}_{5}\right)_{2}\right]\left[\mathrm{FeCl}_{2}\left(\mathrm{C}_{2} \mathrm{O}_{4}\right)\right]\right\}_{n}$ (1); Table S4. Distances between oxalate-bridged iron(III) ions in compound 1. Symmetry operators on the second Fe ion: (i) $1-x$, $1-y, 2-z$; (ii) $-x,-y,-z$; (iii) $2-x, 1-y, 1-z$; (iv) $1-x, 1-y, 1-z$; Figure $\mathrm{S} 2$. The X-ray powder diffraction patterns of coordination polymer 1 (a) prior to and (b) after the humidity treatment; Figure S3. Nyquist plot of $\mathbf{1}$ at $298 \mathrm{~K}$ and (a) $61 \%$ (ambient), (b) $75 \%$, (c) $80 \%$, and (d) $93 \%$ relative humidity (RH). The circles denote experimental impedance data and lines correspond to model impedance obtained by equivalent circuit modeling. The equivalent circuit for all impedance spectra consists of a parallel combination of resistor and constant phase element (CPE 1), which represents the bulk response of the sample, and an additional constant phase element (CPE 2), which models the low-frequency spur arising from the electrode polarization; Figure S4. Conductivity as a function of reciprocal temperature for compound $\mathbf{1}$. Solid lines represent least-squares linear fit to experimental data for the two temperature ranges: from $-90{ }^{\circ} \mathrm{C}$ to $-60{ }^{\circ} \mathrm{C}$ (MT-1) and from $-60{ }^{\circ} \mathrm{C}$ to $70{ }^{\circ} \mathrm{C}$ (HT-1). CCDC 2055768-2055770 contains the supplementary crystallographic data for this paper. These data can be obtained free of charge via http://www.ccdc.cam.ac.uk/conts/retrieving.html (accessed on 22 September 2021) (or from the CCDC, 12 Union Road, Cambridge CB2 1EZ, UK; Fax: +44-1223-336033; E-mail: deposit@ccdc.cam.ac.uk).

Author Contributions: Conceptualization, M.J.; investigation, S.B., K.M., A.Š., T.K., E.W., D.P., Z.J., J.P., and M.J.; resources, K.M., A.Š., E.W., D.P., Z.J., J.P., and M.J.; writing—original draft preparation, 
K.M., A.Š., D.P., J.P., and M.J.; visualization, K.M. and J.P.; funding acquisition, M.J. All authors have read and agreed to the published version of the manuscript.

Funding: This work was funded and supported by the Croatian Science Foundation under Project No. IP-2019-04-5742.

Institutional Review Board Statement: Not applicable.

Informed Consent Statement: Not applicable.

Data Availability Statement: The data presented in this study are available in the Supplementary Materials.

Acknowledgments: T.K. and D.P. acknowledge the support of project CeNIKS co-financed by the Croatian Government and the European Union through the European Regional Development FundCompetitiveness and Cohesion Operational Program (Grant KK.01.1.1.02.0013). The authors thank the PMD ${ }^{2} \mathrm{X}$ X-ray diffraction facility of the Institut Jean Barriol, Universite de Lorraine, for single crystal X-ray diffraction measurements: (http:/ / crm2.univ-lorraine.fr/lab/fr/services/pmd2x, accessed on 22 September 2021).

Conflicts of Interest: The authors declare no conflict of interest

\section{References}

1. Coronado, E.; Espallargas, G.M. Dynamic magnetic MOFs. Chem. Soc. Rev. 2013, 42, 1525-1539. [CrossRef]

2. Espallargas, G.M.; Coronado, E. Magnetic functionalities in MOFs: From the framework to the pore. Chem. Soc. Rev. 2018, 47, 533-557. [CrossRef] [PubMed]

3. Clemente-León, M.; Coronado, E.; Martí-Gastaldoz, C.; Romero, F.M. Multifunctionality in hybrid magnetic materials based on bimetallic oxalate complexes. Chem. Soc. Rev. 2011, 40, 473-497. [CrossRef] [PubMed]

4. Groom, C.R.; Bruno, I.J.; Lightfoot, M.P.; Ward, S.C. The Cambridge Structural Database. Acta Crystallogr. 2016, B72, 171-179. [CrossRef] [PubMed]

5. Kanižaj, L.; Barišić, D.; Torić, F.; Pajić, D.; Molčanov, K.; Šantić, A.; Lončarić, I.; Jurić, M. Structural, Electrical, and Magnetic Versatility of the Oxalate-Based [CuFe] Compounds Containing 2, $2^{\prime}: 6^{\prime}, 2^{\prime \prime}$-Terpyridine: Anion-Directed Synthesis. Inorg. Chem. 2020, 59, 18078-18089. [CrossRef] [PubMed]

6. Kreuer, K.-D. Proton conductivity: Materials and Applications. Chem. Mater. 1996, 8, 610-641. [CrossRef]

7. Lim, D.-W.; Kitagawa, H. Proton Transport in Metal-Organic Frameworks. Chem. Rev. 2020, 120, 8416-8467. [CrossRef] [PubMed]

8. Xie, X.-X.; Yang, Y.-C.; Dou, B.-H.; Li, Z.-F.; Li, G. Proton conductive carboxylate-based metal-organic frameworks. Coord. Chem. Rev. 2020, 404, 213100. [CrossRef]

9. Lim, D.-W.; Sadakiyo, M.; Kitagawa, H. Proton transfer in hydrogen-bonded degenerate systems of water and ammonia in metal-organic frameworks. Chem. Sci. 2019, 10, 16-33. [CrossRef]

10. Sadakiyo, M.; Yamada, T.; Kitagawa, H. Hydrated Proton-Conductive Metal-Organic Frameworks. ChemPlusChem 2016, 81, 691-701. [CrossRef]

11. Yamada, T.; Otsubo, K.; Makiura, R.; Kitagawa, H. Designer coordination polymers: Dimensional crossover architectures and proton conduction. Chem. Soc. Rev. 2013, 42, 6655-6669. [CrossRef]

12. Mon, M.; Vallejo, J.; Pasán, J.; Fabelo, O.; Train, C.; Verdaguer, M.; Ohkoshi, S.-I.; Tokoro, H.; Nakagawa, K.; Pardo, E. A novel oxalate-based three-dimensional coordination polymer showing magnetic ordering and high proton conductivity. Dalton Trans. 2017, 46, 15130-15137. [CrossRef] [PubMed]

13. Maxim, C.; Ferlay, S.; Tokoro, H.; Ohkoshid, S.-I.; Train, C. Atypical stoichiometry for a 3D bimetallic oxalate-based long-range ordered magnet exhibiting high proton conductivity. Chem. Commun. 2014, 50, 5629-5632. [CrossRef]

14. Pardo, E.; Train, C.; Gontard, G.; Boubekeur, K.; Fabelo, O.; Liu, H.; Dkhil, B.; Lloret, F.; Nakagawa, K.; Tokoro, H.; et al. High Proton Conduction in a Chiral Ferromagnetic Metal-Organic Quartz-like Framework. J. Am. Chem. Soc. 2011, 133, 15328-15331. [CrossRef]

15. Sadakiyo, M.; Ōkawa, H.; Shigematsu, A.; Ohba, M.; Yamada, T.; Kitagawa, H. Promotion of Low-Humidity Proton Conduction by Controlling Hydrophilicity in Layered Metal-Organic Frameworks. J. Am. Chem. Soc. 2012, 134, 5472-5475. [CrossRef]

16. Ōkawa, H.; Shigematsu, A.; Sadakiyo, M.; Miyagawa, T.; Yoneda, K.; Ohba, M.; Kitagawa, H. Oxalate-Bridged Bimetallic Complexes $\left\{\mathrm{NH}(\text { prol })_{3}\right\}\left[\mathrm{MCr}(\mathrm{ox})_{3}\right]\left(\mathrm{M}=\mathrm{Mn}^{\mathrm{II}}, \mathrm{Fe}^{\mathrm{II}}, \mathrm{Co}^{\mathrm{II}} ; \mathrm{NH}(\text { prol })_{3}{ }^{+}=\mathrm{Tri}(3\right.$-hydroxypropyl)ammonium) Exhibiting Coexistent Ferromagnetism and Proton Conduction. J. Am. Chem. Soc. 2009, 131, 13516-13522. [CrossRef] [PubMed]

17. Sadakiyo, M.; Yamada, T.; Kitagawa, H. Rational Designs for Highly Proton-Conductive Metal-Organic Frameworks. J. Am. Chem. Soc. 2009, 131, 9906-9907. [CrossRef] [PubMed]

18. Sadakiyo, M.; Yamada, T.; Kitagawa, H. Proton Conductivity Control by Ion Substitution in a Highly Proton-Conductive Metal-Organic Framework. J. Am. Chem. Soc. 2014, 136, 13166-13169. [CrossRef] 
19. Sadakiyo, M.; Yamada, T.; Honda, K.; Matsui, H.; Kitagawa, H. Control of Crystalline Proton-Conducting Pathways by WaterInduced Transformations of Hydrogen-Bonding Networks in a Metal-Organic Framework. J. Am. Chem. Soc. 2014, 136, 7701-7707. [CrossRef]

20. Nagarkar, S.S.; Unni, S.M.; Sharma, A.; Kurungot, S.; Ghosh, S.K. Two-in-One: Inherent Anhydrous and Water-Assisted High Proton Conduction in a 3D Metal-Organic Framework. Angew. Chem. Int. Ed. 2014, 53, 2638-2642. [CrossRef]

21. Wang, X.; Qin, T.; Bao, S.S.; Zhang, Y.C.; Shen, X.; Zheng, L.M.; Zhu, D.R. Facile synthesis of a water stable 3D Eu-MOF showing high proton conductivity and its application as a sensitive luminescent sensor for $\mathrm{Cu}^{2+}$ ions. J. Mater. Chem. A 2016, 4, 16484-16489. [CrossRef]

22. Tominaka, S.; Coudert, F.; Dao, T.D.; Nagao, T.; Cheetham, A.K. Insulator-to-Proton-Conductor Transition in a Dense MetalOrganic Framework. J. Am. Chem. Soc. 2015, 137, 6428-6431. [CrossRef] [PubMed]

23. Yamada, T.; Sadakiyo, M.; Kitagawa, H. High Proton Conductivity of One-Dimensional Ferrous Oxalate Dihydrate. J. Am. Chem. Soc. 2009, 131, 3144-3145. [CrossRef] [PubMed]

24. Xu, H.-B.; Wang, Z.-M.; Liu, T.; Gao, S. Synthesis, Structure, and Magnetic Properties of (A) $\left[\mathrm{Fe}^{\mathrm{III}}\left(\mathrm{oxalate}_{\mathrm{Cl}} \mathrm{Cl}_{2}\right](\mathrm{A}=\mathrm{Alkyl}\right.$ Ammonium Cations) with Anionic 1D [Fe ${ }^{\mathrm{III}}$ (oxalate)Cl $]_{2}^{-}$Chains. Inorg. Chem. 2007, 46, 3089-3096. [CrossRef] [PubMed]

25. CrysAlis PRO; Rigaku Oxford Diffraction Ltd.: Yarnton, UK, 2018.

26. SAINT V8.34A; Bruker AXS Inc.: Madison, WI, USA, 2013.

27. Sheldrick, G.M. SHELXT_-Integrated space-group and crystal structure determination. Acta Crystallogr. 2015, A71, 3-8. [CrossRef] [PubMed]

28. Sheldrick, G.M. Crystal structure refinement with SHELXL. Acta Crystallogr. 2015, C71, 3-8.

29. Spek, A.L. Single-crystal structure validation with the program PLATON. J. Appl. Crystallogr. 2003, 36, 7-13. [CrossRef]

30. Spek, A.L. Structure validation in chemical crystallography. Acta Crystallogr. 2009, D65, 148-155. [CrossRef]

31. Farrugia, L.J. ORTEP-3 for Windows-A version of ORTEP-III with a Graphical User Interface (GUI). J. Appl. Crystallogr. 1997, 30, 565. [CrossRef]

32. Macrae, C.F.; Sovago, I.; Cottrell, S.J.; Galek, P.T.A.; McCabe, P.; Pidcock, E.; Platings, M.; Shields, G.P.; Stevens, J.S.; Towler, M.; et al. Mercury 4.0: From visualization to analysis, design and prediction. J. Appl. Crystallogr. 2020, 53, 226-235. [CrossRef]

33. Cliffe, M.J.; Goodwin, A.L. PASCal: A principal axis strain calculator for thermal expansion and compressibility determination. J. Appl. Crystallogr. 2012, 45, 1321-1329. [CrossRef]

34. Khan, O. Molecular Magnetism; Wiley-VCH: New York, NY, USA, 1993; p. 258.

35. Kanižaj, L.; Šenjug, P.; Pajić, D.; Pavić, L.; Molčanov, K.; Jurić, M. Magnetic and Electrical Behaviors of the Homo- and Heterometallic 1D and 3D Coordination Polymers Based on the Partial Decomposition of the $\left[\mathrm{Cr}\left(\mathrm{C}_{2} \mathrm{O}_{4}\right)_{3}\right]^{3-}$ Building Block. Materials 2020, 13, 5341. [CrossRef] [PubMed]

36. Panda, M.K.; Runčevski, T.; Sahoo, S.C.; Belik, A.A.; Nath, N.K.; Dinnebier, R.E.; Naumov, P. Colossal positive and negative thermal expansion and thermosalient effect in a pentamorphic organometallic martensite. Nat. Commun. $2014,5,4811$.

37. Lončarić, I.; Popović, J.; Despoja, V.; Burazer, S.; Grgičević, I.; Popović, D.; Skoko, Ž. Reversible Thermosalient Effect of N'-2Propylidene-4-hydroxybenzohydrazide Accompanied by an Immense Negative Compressibility: Structural and Theoretical Arguments Aiming toward the Elucidation of Jumping Phenomenon. Cryst. Growth Des. 2017, 17, 4445-4453. [CrossRef]

38. Yao, Z.-S.; Guan, H.; Shiota, Y.; He, C.-T.; Wang, X.-L.; Wu, S.-Q.; Zheng, X.; Su, S.-Q.; Yoshizawa, K.; Kong, X.; et al. Giant anisotropic thermal expansion actuated by thermodynamically assisted reorientation of imidazoliums in a single crystal. Nat. Commun. 2019, 10, 4805. [CrossRef] [PubMed]

39. Zhang, B.; Wang, Z.; Fujiwara, H.; Kobayashi, H.; Kurmoo, M.; Inoue, K.; Mori, T.; Gao, S.; Zhang, Y.; Zhu, D. Tetrathiafulvalene $\left[\mathrm{Fe}^{\mathrm{III}}\left(\mathrm{C}_{2} \mathrm{O}_{4}\right) \mathrm{Cl}_{2}\right]$ : An Organic-Inorganic Hybrid Exhibiting Canted Antiferromagnetism. Adv. Mater. 2005, 17, 1988-1991. [CrossRef]

40. Zhang, B.; Wang, Z.; Zhang, Y.; Takahashi, K.; Okano, Y.; Cui, H.; Kobayashi, H.; Inoue, K.; Kurmoo, M.; Pratt, F.L.; et al. Hybrid Organic-Inorganic Conductor with a Magnetic Chain Anion: $\kappa-B_{E T S}\left[\mathrm{Fe}^{\mathrm{III}}\left(\mathrm{C}_{2} \mathrm{O}_{4}\right) \mathrm{Cl}_{2}\right][\mathrm{BETS}=$ Bis(ethylenedithio)tetraselenafulvalene]. Inorg. Chem. 2006, 45, 3275-3280. [CrossRef]

41. Armentano, D.; Mastropietro, T.F.; De Munno, G.; Rossi, P.; Lloret, F.; Julve, M. New Extended Magnetic Systems Based on Oxalate and Iron(III) Ions. Inorg. Chem. 2008, 47, 3772-3786. [CrossRef]

42. Mastropietro, T.F.; Marino, N.; De Munno, G.; Lloret, F.; Julve, M.; Pardo, E.; Armentano, D. Selective Guest Inclusion in Oxalate-Based Iron(III) Magnetic Coordination Polymers. Inorg. Chem. 2016, 55, 11160-11169. [CrossRef]

43. Sanda, S.; Biswas, S.; Konar, S. Study of Proton Conductivity of a 2D Flexible MOF and a 1D Coordination Polymer at Higher Temperature. Inorg. Chem. 2015, 54, 1218-1222. [CrossRef]

44. Morikawa, S.; Yamada, T.; Kitagawa, H. Crystal structure and proton conductivity of a one-dimensional coordination polymer, $\left\{\mathrm{Mn}(\mathrm{DHBQ})\left(\mathrm{H}_{2} \mathrm{O}\right)_{2}\right\}$. Chem. Lett. 2009, 38, 654-655. [CrossRef]

45. Guo, Z.-C.; Shi, Z.-Q.; Wang, X.-Y.; Li, Z.-F.; Li, G. Proton conductive covalent organic frameworks. Coord. Chem. Rev. 2020, 422, 213465. [CrossRef] 